\title{
PERFORMANCE ANALYSIS OF GALVALUME STEEL SHEETS FOR METALIC ROOF TILES*
}

Claudio Pereira Diogo ${ }^{1}$ Willy Ank de Morais ${ }^{2}$

\begin{abstract}
A lot of galvalume/aluzinc steel sheet was furnished to a metallic roof manufacturer intended for tile fabrication. But, according with the roof manufacturer, that coils develops a different superficial aspect during processing. The purpose of this work was to provide an explanation for the appearance of the observed surface on one side of the coils. In order to find out the origin of the problem, mechanical and microstructural characterization tests were done at INSPEBRAS with the support of a partner laboratory. The results are described in this paper with their analysis and conclusions.
\end{abstract}

Keywords: Galvalume; Aluzinc; Etallic tile; Carbon steel; Coils.

1 Production Engineer, Technical and Commercial Consultant of FALCATE Industrial and Metals Ltda. and UNIMONTE student, Santos, SP, Brazil.

2 MSc, Metallurgical Engineer, Professor at UNISANTA and Technical Consultant of INSPEBRAS, Santos, SP, Brazil. 


\section{INTRODUCTION}

A lot of galvalume/aluzinc steel sheet was furnished to a metallic roof manufacturer intended for tile fabrication. But, according with the roof manufacturer, that coils develops a different superficial aspect during processing. Also as informed, a 'dark aspect' on the surface in those regions appears mainly when the sheet is formed in its final tile form, impairing its application and generating a claim from supplier.

Figure 1 summarizes, graphically, what it was described formerly. The localization of this region in the coils is near one of the mill's edge. This band is contained in the samples identified as "A", according making on the furnished samples. The mentioned surface characteristic normally is not visible on plates before forming or processing by straightener/flattener/leveler equipment.
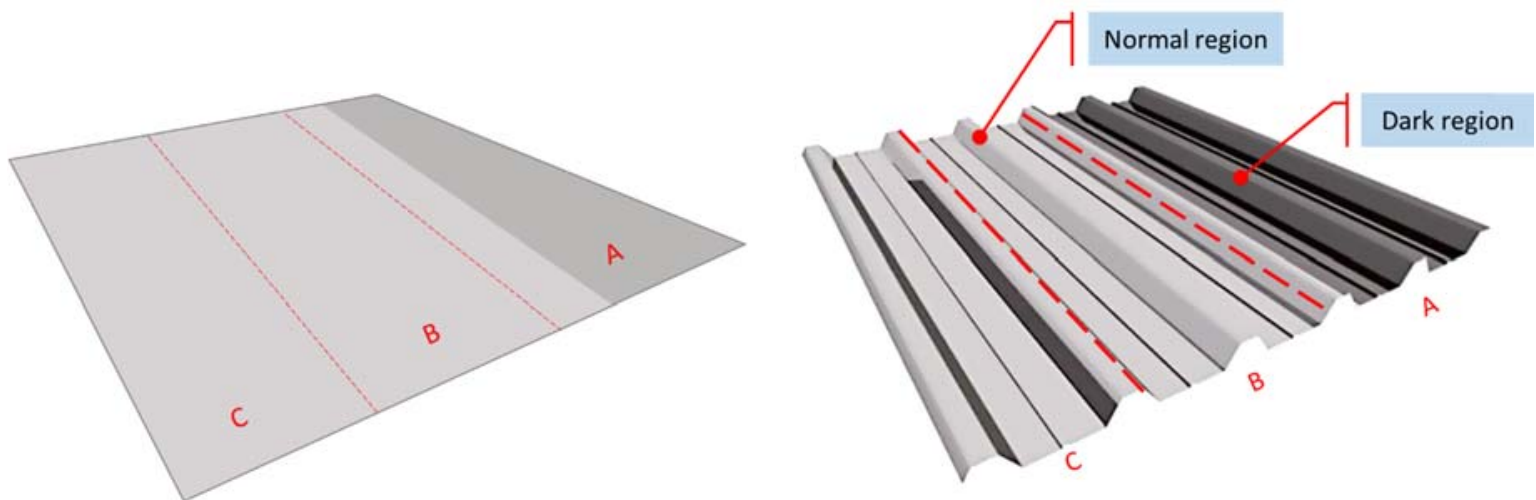

Figure 1. Left: galvalume/aluzinc sheets representation of the regions sampled. Right: representation of the problem and the association with the regions sampled.

The purpose of this work was to provide an explanation for the appearance of the observed surface on one side of the coils. In order to find out the origin of the problem, mechanical and microstructural characterization tests were done at INSPEBRAS with the support of a partner laboratory. The results are described in this paper with their analysis and conclusions.

\section{MATERIAL AND METHODS}

It was sampled three coils, each one obtained by its width $(w=1200 \mathrm{~mm})$ from a different nominal thickness coil: $\mathrm{t}=0.35 ; 0.43$ and $0.50 \mathrm{~mm}$. These samples were identified as following: "413306 SLB02 0502CL"; "413339 SLAD4 0432CL" and "413277 SLAD3 0352CL" for 0.50; 0.43 and $0.35 \mathrm{~mm}$ nominal thickness, respectively. From each coil were cut three different samples labeled "A"; "B" and " $C$ " which have from 359 to $490 \mathrm{~mm}$ width. Thus, a grand total of 9 (nine) pieces (samples) were delivered by representative supplier to be analyzed according to showed by Figure 1. Each received sample was identified as $99 X$, where 99 is the nominal thickness, in centesimal millimeters, and $X$ is the respective position along the width: $A$ (near where the problem occurred), B (center) and C (other mill's edge). Figure 2 shows the visual aspect of all samples. Moreover, for the sample 99A it was employed another classification: 99A.N for normal region and 99A.A for 'abnormal' region, in which occurs the problem reported by a metallic roof manufacturer. 


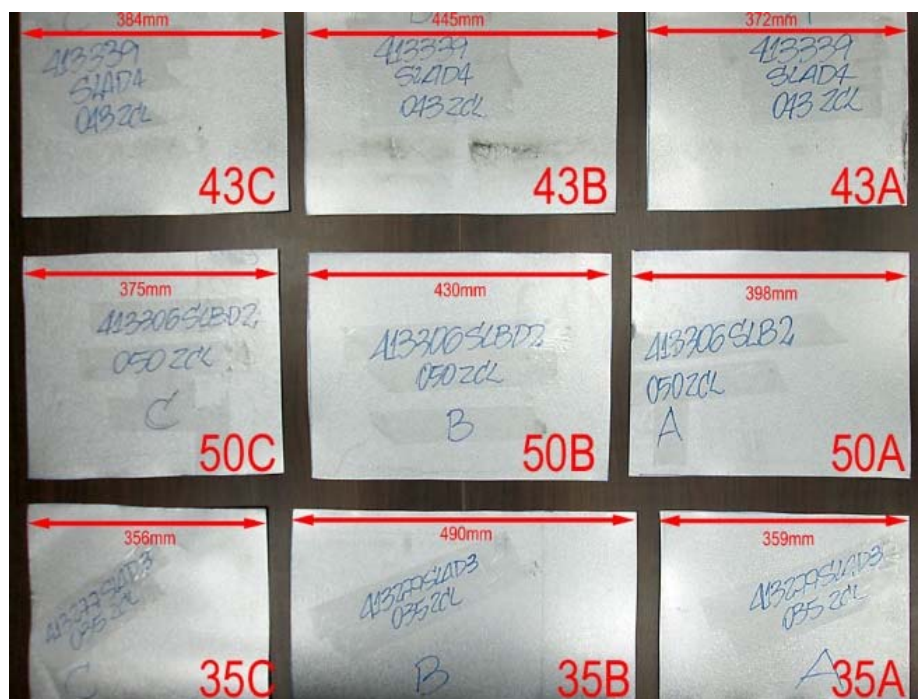

Figure 2. The used samples of galvalume/aluzinc steel coils (1200mm nominal wide). The numbers shown the width of the samples and the identification code that was adopted here.

Figure 3 shows the visual aspect of the sample 43A. It was the only sample, among all received, with a slight surface difference visible even to the naked eye. In the Figure 3, it can be noted an abnormal "bright band" near the mills edge of the sheet (sample) 43A. This region was identified as "43A.A" and has an approximate size (width) of $106 \mathrm{~mm}$. That region is more prominent in the lower surface of the sheet (inner side of the coil) than the upper. The remainder of the surface, named as "43A.N", is very similar to the other's samples surfaces (43B and 43C).

Thus, in this analysis it was adopted the 'normal' (or .N) condition to designate the standard surface aspect for 35.X; 43.X and 50.X (where: X="A", "B" and "C") samples away $106 \mathrm{~mm}$ for edge. Similarly, the region near the mill's edge at "A" side will be considered as 'abnormal' (or .A). Optical microscopy, tensile tests, microhardness and metallography were used in order to describe better the difference between samples with surfaces 'abnormal' and XXA.N 'normal'.
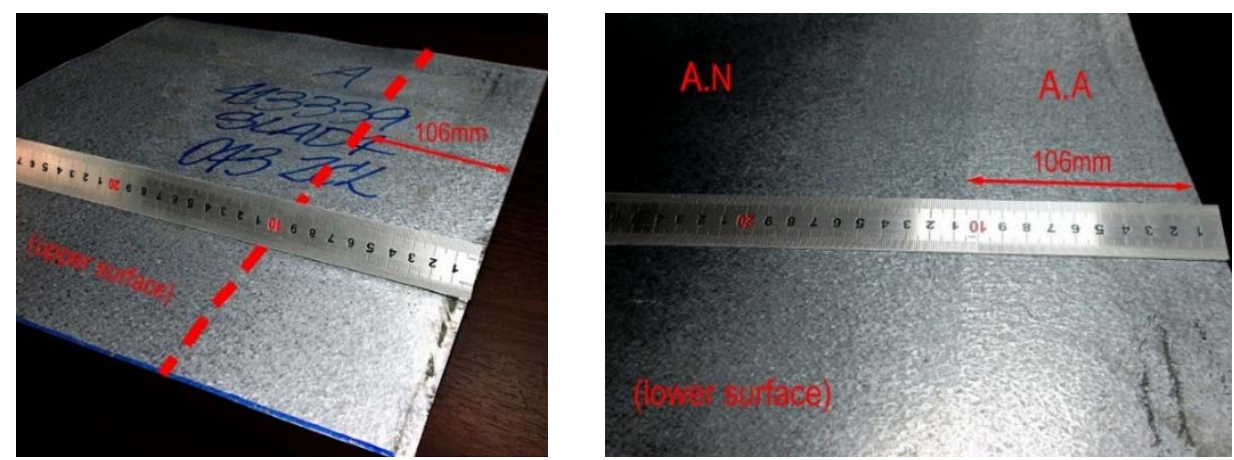

Figure 3. Abnormal "bright band" on the mill's edge of the sample 43A. The characteristic is more visible on lower surface.

\section{RESULTS AND DISCUSSION}

\subsection{Surface: Normal (N) and Abnormal (A)}

Figure 4 shows several pictures taken by light microscopy (stereo microscope) through five increased magnifications for the sample $43 \mathrm{~A}$. 


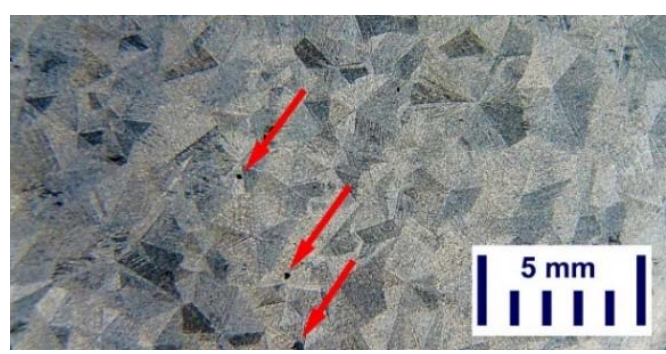

Abnormal (10X)

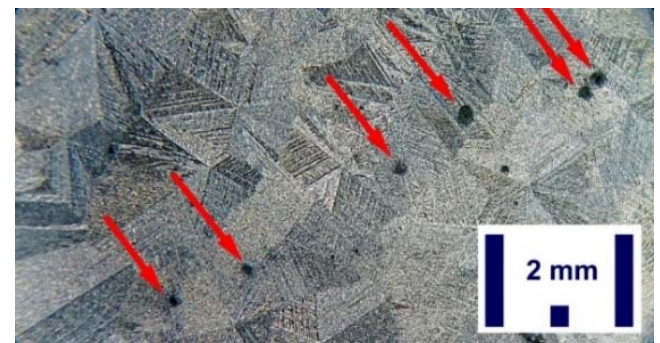

Abnormal (20X)

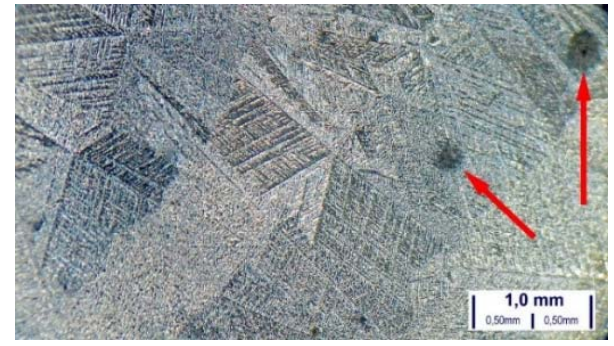

Abnormal (40X)

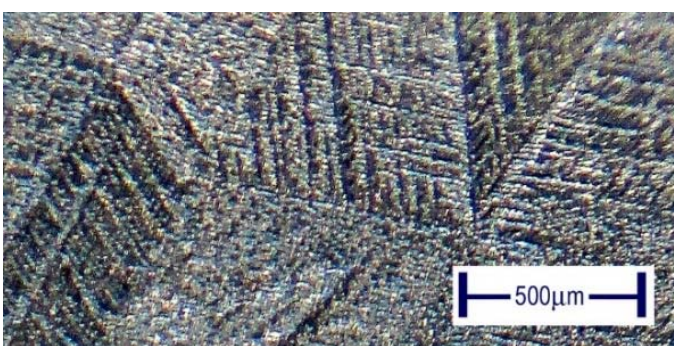

Abnormal (80X)

Normal (80X)

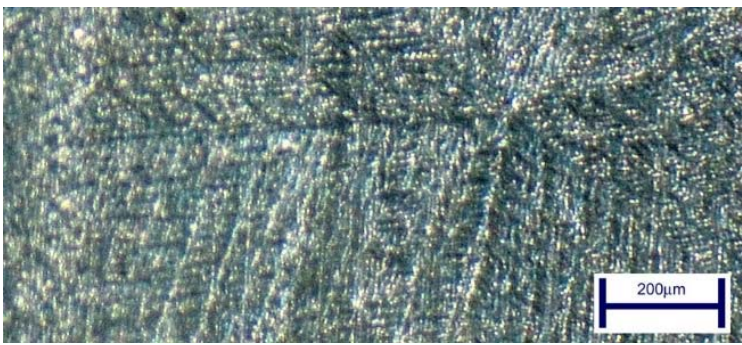

Normal (200X)

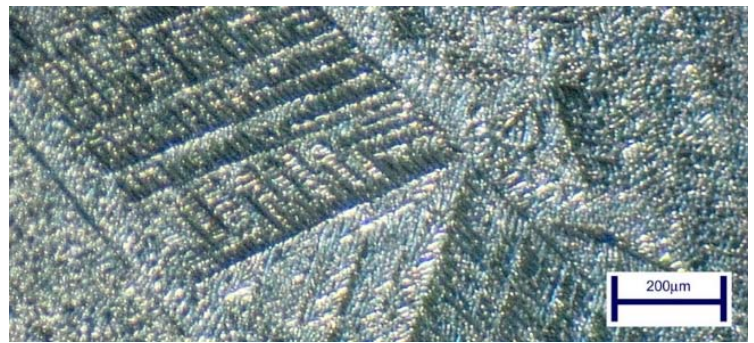

Abnormal (200X)

Figure 4. Normal (N) and abnormal (A) surfaces on sample 43A as seen by light microscopy.

It can be noted by the photos taken by stereo microscope (Figure 4) that the bright region is formed by a coarse deformation pattern on aluminum-zinc-silicon alloy (galvalume/aluzinc layer), which is more easily seen at magnifications of $200 \mathrm{X}$. Whereas the galvalume/aluzinc layer is homogeneous, it seems that the steel substrate deforms more intensely in the 'abnormal' region (A.A) than in the other 
(A.N). This difference deformation of the steel substrate can generate the coarse-like deformation structure of the aluminum-zinc-silicon alloy crystals as viewed on surface (Figure 4 at 200X).

Moreover, it is noted that there are 'dark spots' on abnormal (43A.A) surface, many of them visible on lower magnifications (10X and 20X). Figure 5 shows one of these spots with more details and reveals that these stains are a kind of localized oxidation that occurs preferably between the walls of the aluminum-zinc-silicon alloy crystals.

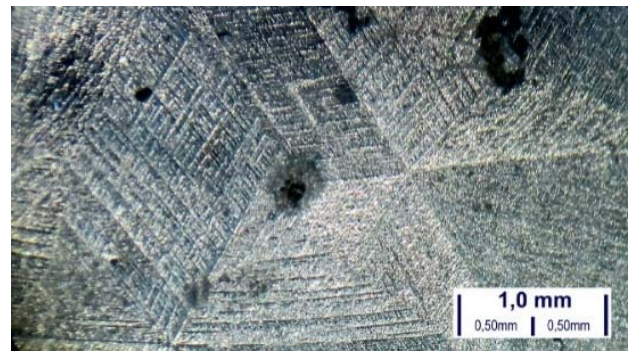

$40 X$

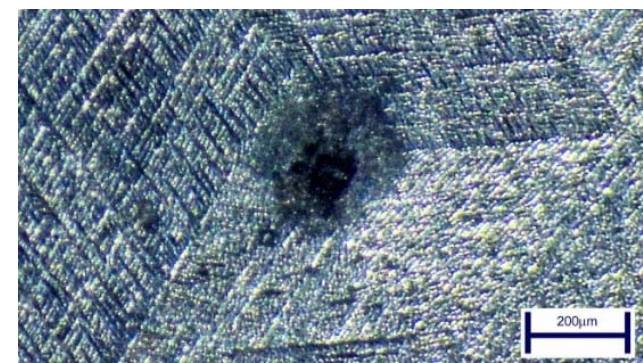

200X

Figure 5. 'Dark spot' viewed on surface of the sample 43A.A, as seen by light microscopy.

The dark spot/stain observed is very similar to the feature known as "wet storage stain". In this case, galvalume/aluzinc has excellent durability in the atmosphere because of the protective, air-formed oxide that forms on the surface. However, if there is no free access to dry air and if water or moisture is present, a faster type of corrosion by the forming of hydrated aluminum oxide $\left(\mathrm{Al}_{2} \mathrm{O}_{3} \cdot 3 \mathrm{H}_{2} \mathrm{O}\right)$ occurs. Under these conditions, due to the lack of an inhibiting oxide fil, degradation of the surface appearance of Galvalume sheet can occur in as little as 24-48 hours.

In the present case, it is possible that the tension/deformation imposed by the straightener/flattener/leveler equipment on customer facilities had promoted sufficient deformation on galvalume/aluzinc layer, on surface 43A.A, in order to generate tiny cracks. These small apertures, mainly on crystals interfaces, permits air moisture to enter producing dark oxidation $\left(\mathrm{Al}_{2} \mathrm{O}_{3} \cdot 3 \mathrm{H}_{2} \mathrm{O}\right)$ in a mechanism very similar to the "wet storage stain". Obviously, with more intense deformation (like that used during tile forming) more microcracks are formed. These microcracks are paths through the layer, which moisture enters producing wet oxidation and so darkening the obtained surface.

\subsection{Mechanical Properties - Tensile Test}

In order to understand the behavior of the steel substrate, just below the galvalume/aluzinc surface, tensile test specimens were sampled from $0.50 ; 0.43$ and $0.35 \mathrm{~mm}$ nominal thickness sheets. In all cases, there were sampled the normal (50A.A, 43A.A and 35A.A) and abnormal (50A.N, 43A.N and 35A.N) regions as showed by Figure 6. Important to remember that only sheet 43A ("413339 SLAD4 0432CL" - A) presents a different surface feature in the condition 'as received' from supplier. The others specimens type "N" were sampled in the same region, up to $106 \mathrm{~mm}$ from mill's edge, from specimen 43A.N. All specimens had the dimensions showed by Figure 7. It was used an electro mechanical tensile testing machine equipped with electronic strain gage, fixed on each specimen to determine precisely the tensile stress-strain engineering curve. During tensile tests, load was applied with a constant velocity of $10 \mathrm{~mm} / \mathrm{min}$ from beginning to the fracture of all specimens. 

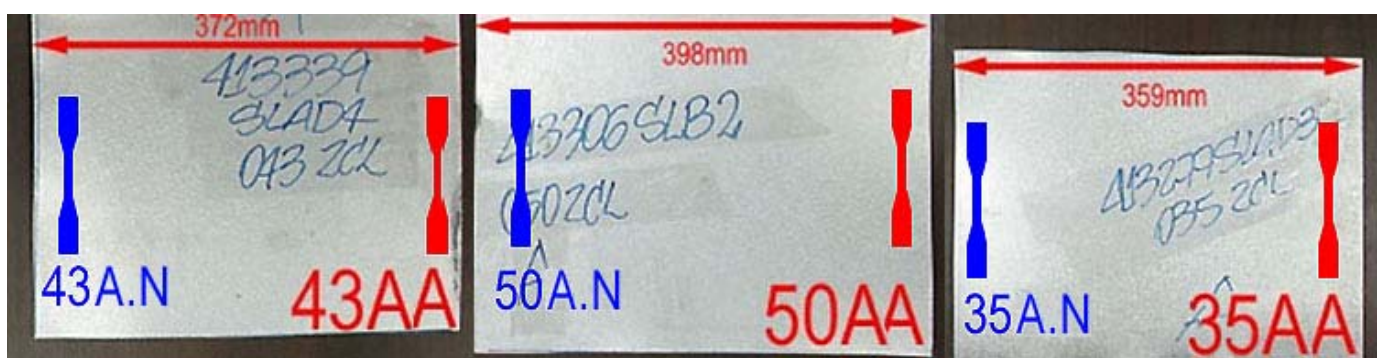

Figure 6. Tensile test specimen sampling: left side (blue or XXA.N) - normal; right side (red or XXA.A) - abnormal.

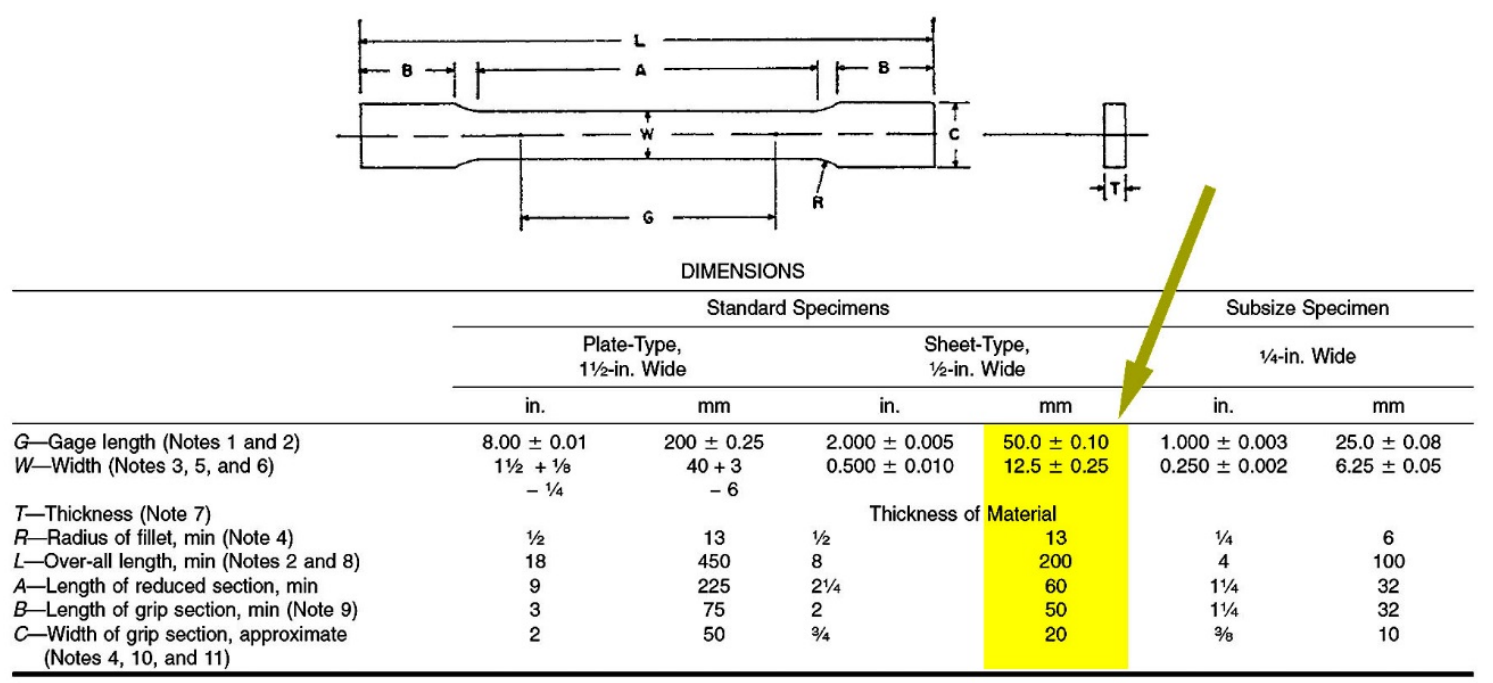

Figure 7. Rectangular tensile test specimen used for this work (highlighted): $G=50 \mathrm{~mm} ; \mathrm{W}=12,5 \mathrm{~mm}$; $\mathrm{t}=$ sample.

Figure 8 summarizes the results obtained with samples from normal and abnormal regions and the graph of Figure 9 shows a comparison between the mechanical behaviors of these two regions. As can be noted by Figure 6, this variation of mechanical behavior occurs in very near regions of the sheets. The separation of each normal-abnormal sample is only about $350 \mathrm{~mm}$.

The stress-strain curve obtained from 'abnormal' indicates that the steel in that region has undergone a process of strain aging. As described by supplier representative (see Figure 1) and as well measured in this work (see Figure 3), the verified strain aging occurred in a very specific region, near one of the mill's edge. This scenario indicates that some kind of treatment of misprocessing operation occurred over $106 \mathrm{~mm}$ (or 4.1 inches) from one edge of the analyzed coils.

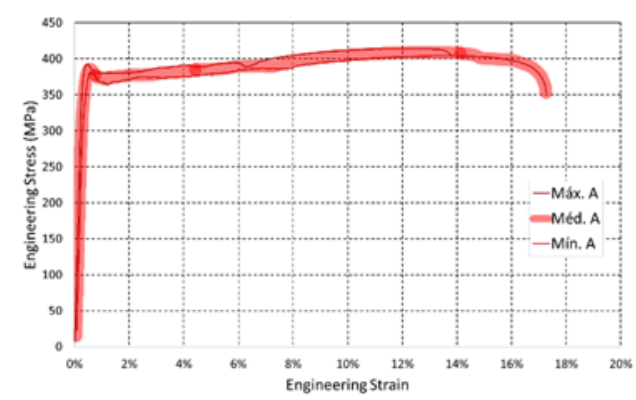

'Abnormal' region

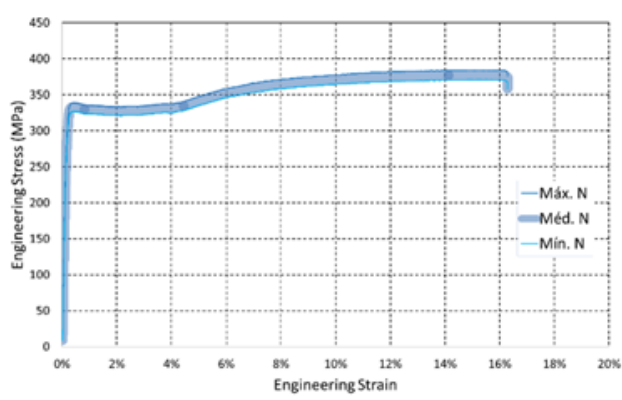

'Normal' region

Figure 8. Tensile stress-strain curve from 'abnormal' $(A)$ and 'normal' $(N)$ regions of the received sheet samples. 
The surfaces of the tensile test specimens showed a remarkable difference in terms of the galvalume/aluzinc layer aspect. While normal samples behaved as expected, with steel and layer deforming together, samples obtained in the abnormal regions do not. A 'fish scale' feature was observed at galvalume/aluzinc layer near fracture on each tensile specimen from abnormal region. Figure 9 illustrates this difference pointed out by stereo microscopy surface photos.

The same cause that produced the detected strain aging can be associated to a more fragile behavior of galvalume/aluzinc layer in the 'abnormal' region of sheet. A more fragile layer, produced by an unwanted thermal treatment, can aid to explain the different feature observed on 'abnormal' (A) and 'normal' (N) surfaces. Depending on type of thermal cycle submitted on the analysed coils, it can produce both strain aging and layer fragilization.

\subsection{Mechanical Properties - Microhardness}

Microhardness Vickers was measured on transversal section of the samples. It was employed a load of 50gf in the positions showed by Figure 10 and it was obtained the results presented by Table 1.

Table 1. Microhardness values $\left(\mu \mathrm{HV}_{50}\right)$ by sample and position ('abnormal' and 'normal').

\begin{tabular}{cccccc}
\hline & \multicolumn{2}{c}{ SAMPLES } & \multicolumn{2}{c}{ Abnormal position (X=A) } & \multicolumn{2}{c}{ Normal position (X=N) } \\
\hline Identification & Real Thickness (mm) & Near surface & Center & Near surface & Center \\
\hline 35A.X & 0,360 & 159 & 158 & 173 & 180 \\
\hline 43A.X & 0,447 & 152 & 159 & (same) & 151 \\
\hline 50A.X & 0,478 & (same) & 123 & (same) & 193 \\
\hline & Average : & 145 & 147 & 173 & 175 \\
\hline & Std. Desviation : & 19 & 21 & 21 & 22 \\
\hline
\end{tabular}

Microhardness measurement shown that abnormal samples have a little less hardness $\left(150 \mu \mathrm{HV}_{50}\right.$ general average) than normal ones $\left(174 \mu \mathrm{HV}_{50}\right.$ general average). Considering that penetration hardness depends on the plastic behavior of the samples, one can conclude that one set of samples (abnormal) possess a different mechanical behavior than the other set (normal).

\subsection{Metallurgical Structure}

All samples present a microstructure formed by fine equiaxed grains with a sparse presence of carbides as summarized by Figure 11. Figure 12 presents a direct comparison between normal and abnormal regions in the sheets. Figure 13 and 14 shows the metallographic microstructures of selected sheets in the normal (Figure 13) and abnormal (Figure 14) regions.

Thickness of galvalume/aluzinc layer was homogeneously constant in all samples around $20 \mu \mathrm{m}$ in all samples. The measured grain size (according to the ASTM E112) varied between \#10 $(\approx 12 \mu \mathrm{m})$ to \#12 $(\approx 5 \mu \mathrm{m})$. The average grain size presents slight variations through thickness and a stronger dependence on sample thickness as it can be seen in Figure 12 and 13.

A direct comparison of the micrographs of normal and abnormal regions (Figure $12 \mathrm{x}$ Figure 13) does not show major differences between them. Only a slight difference on the amount of fine carbides can be noted in the normal samples. 


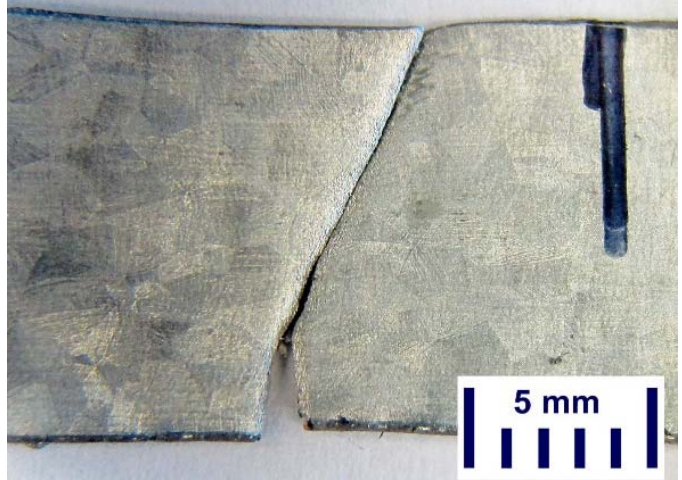

Sample 43A.N (Normal - 10X)

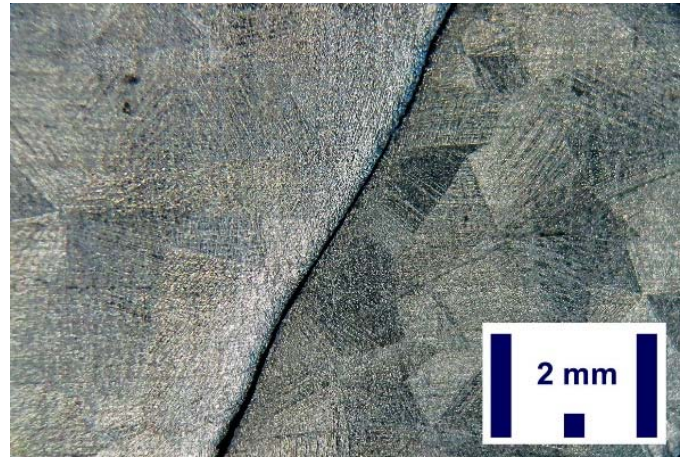

Sample 35A.N (Normal - 20X)

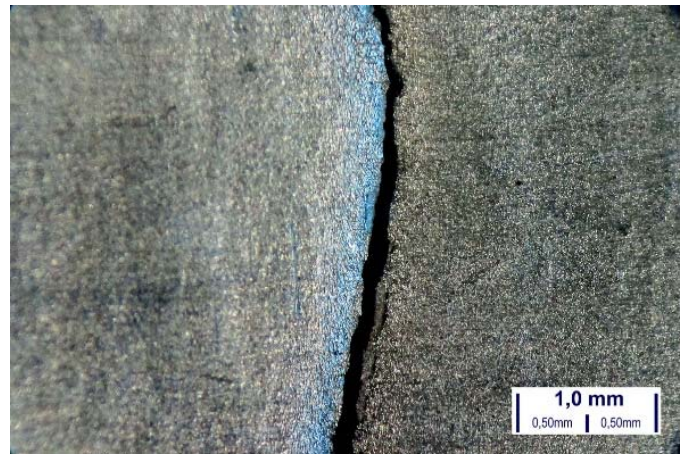

Sample 50A.N (Normal - 40X)

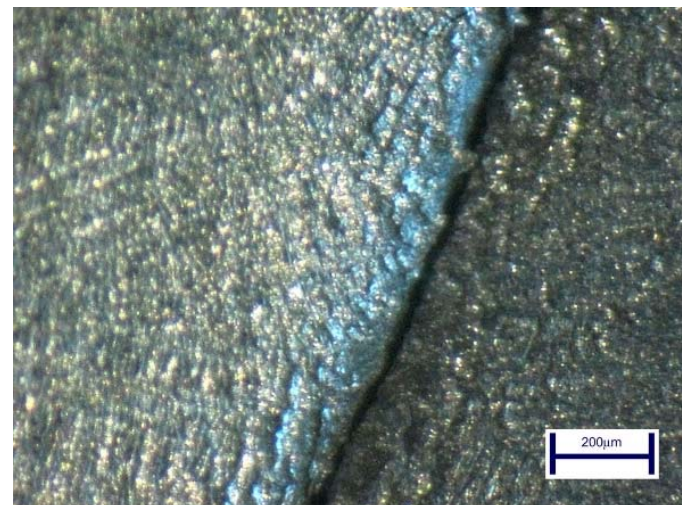

Sample 43A.N (Normal - 200X)

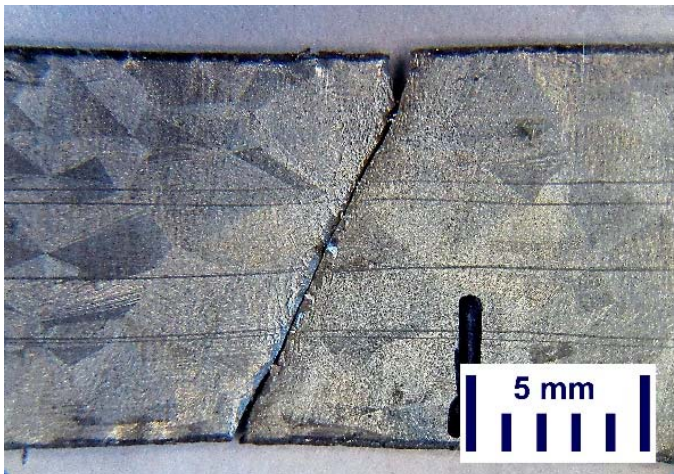

Sample 50A.A (Abnormal - 10X)

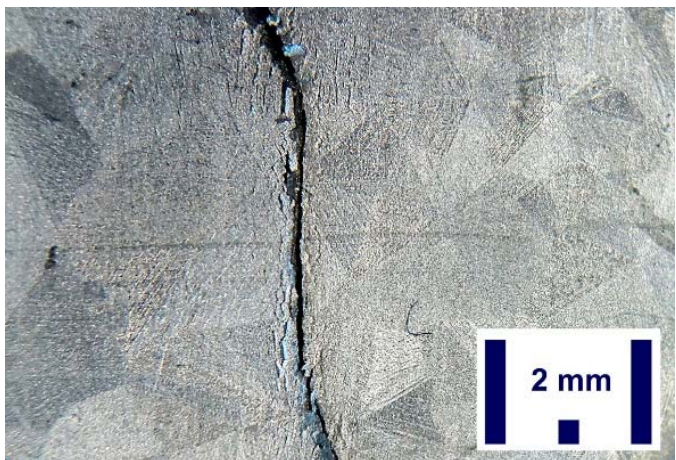

Sample 35A.A (Abnormal - 20X)

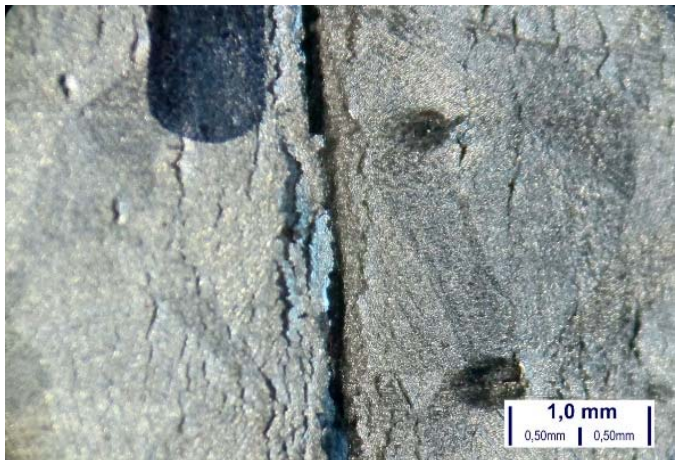

Sample 43A.A (Abnormal - 40X)

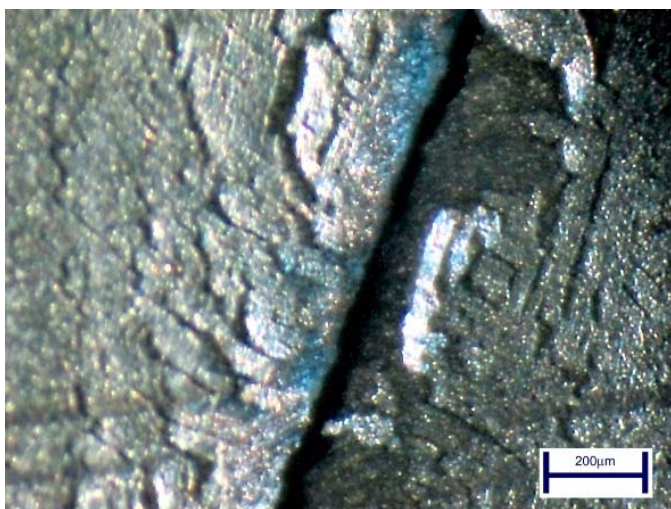

Sample 50A.A (Abnormal - 200X)

Figure 9. Tensile test samples surfaces as viewed near fracture with increased magnifications by stereo microscopy. 

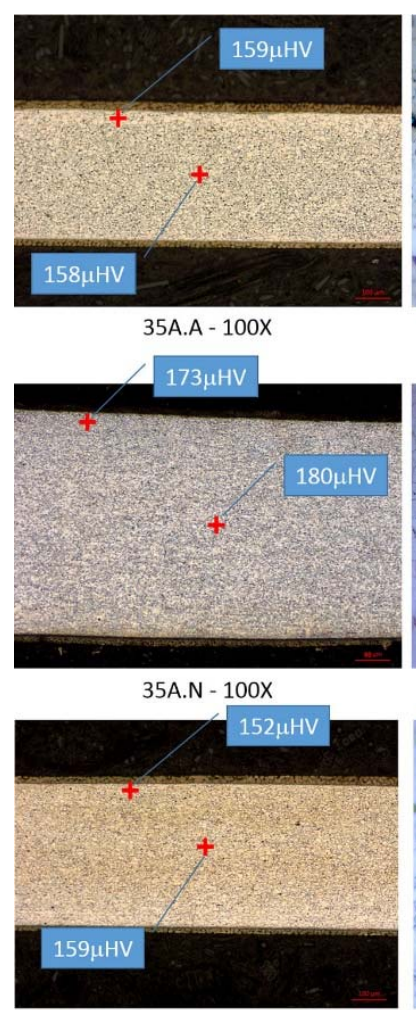

43A.A - 100X

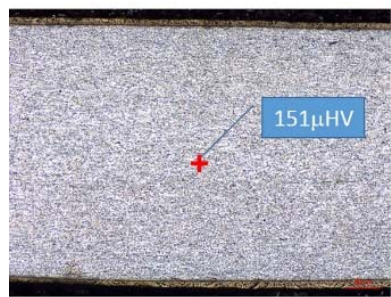

43A.N - 200X

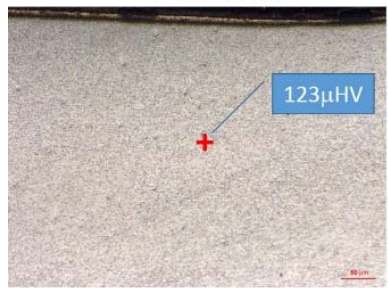

50A.A - 200X

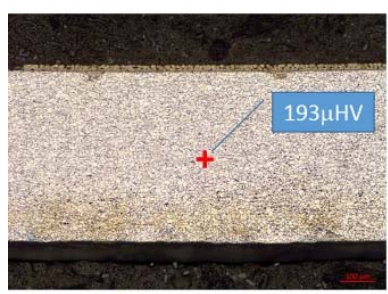

50A.N - 100X

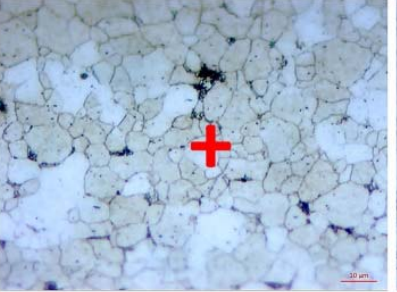

35A.A - Center - 1000X

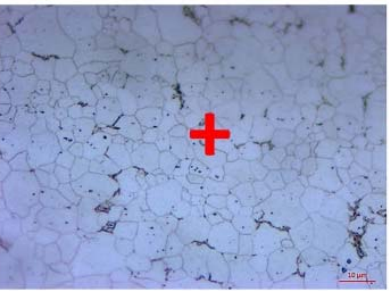

35A.N - Center - 1000X

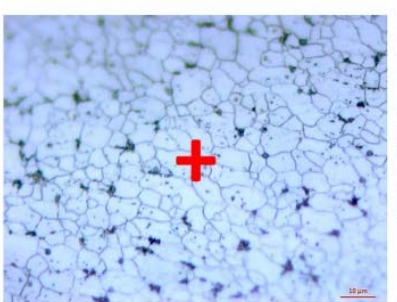

43A.A - Center - 1000X

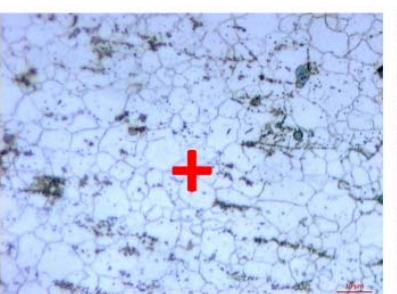

43A.N - Center - 1000X

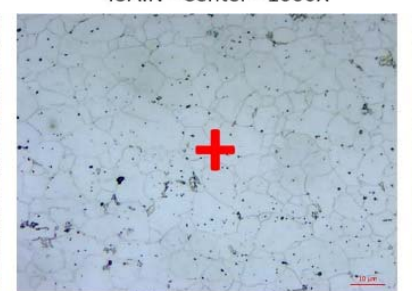

50A.A - Center - 1000X

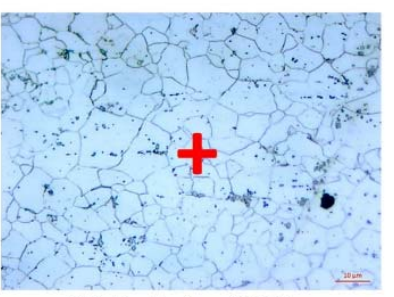

50A.N - Center - 1000X

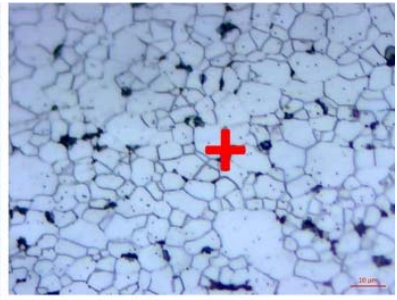

35A.A - Sup - 1000X

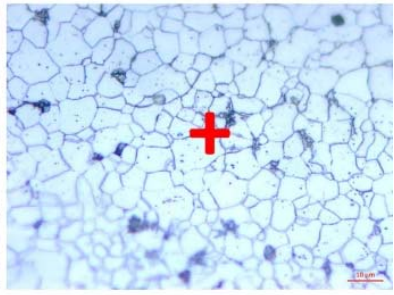

35A.N - Sup - 1000X

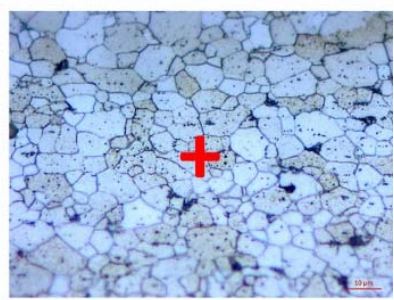

43A.A - Sup - $1000 x$

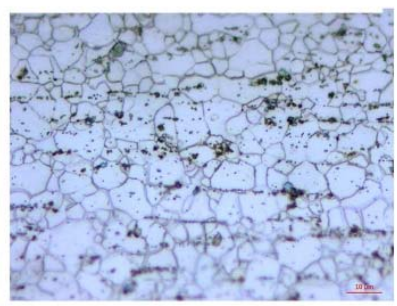

43A.N - Sup - $1000 \mathrm{X}$

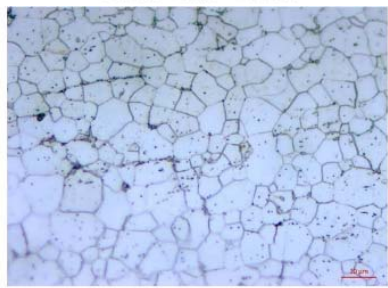

50A.A - Sup - $1000 X$

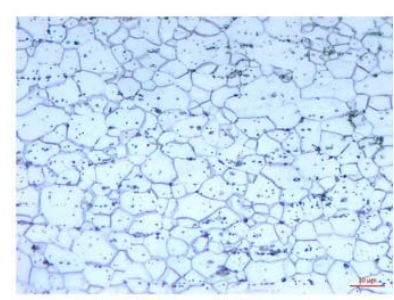

50A.N - Sup - 1000X

Figure 10. Microhardness $\left(\mu \mathrm{H} \mathrm{V}_{50}\right)$ measurement positions on samples and values obtained. (Transversal sections). 


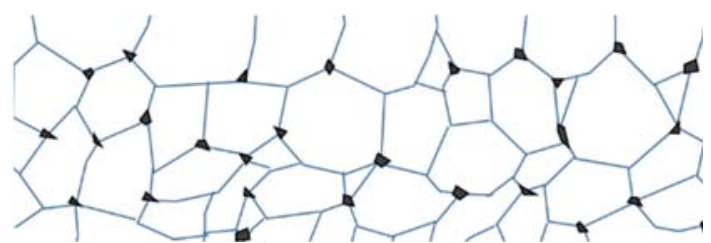

Grain size distribution (homogeneous)

Arrangement of Carbides (Cementite type III)

Figure 11. Scheme of the types of microstructures that were observed in the metallographic analysis.

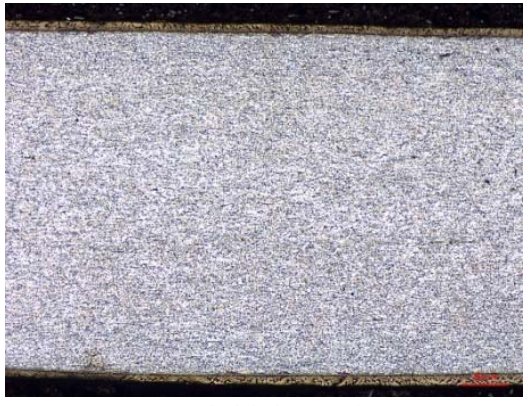

43A.N (200x)

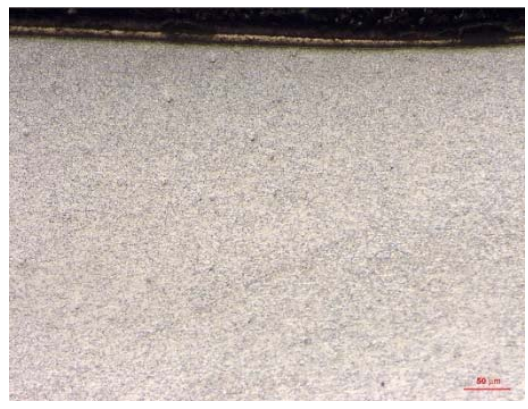

50A.A (200x)

Figure 12. Comparison of normal and abnormal samples through low magnification.

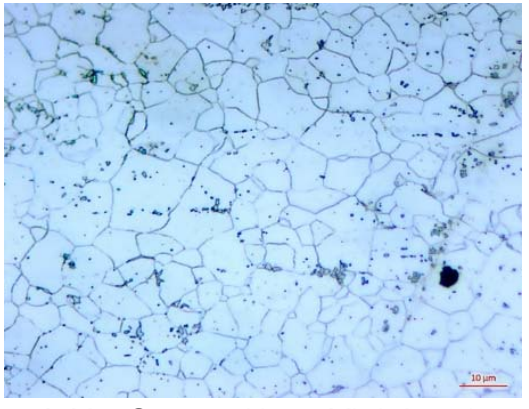

50A.N - Center $(1000 \mathrm{X}) / \mathrm{d} \approx 5,1 \mu \mathrm{m}$

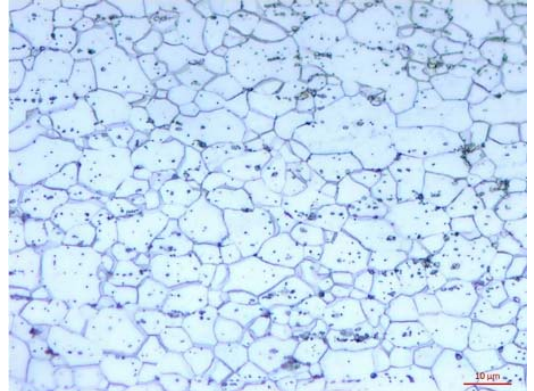

50A.N - Near surface $(1000 X) / d \approx 6,1 \mu \mathrm{m}$

Figure 13. Micrographs of normal sample 50A.N (2\% Nital Etch). The average grain size (d) are indicated.

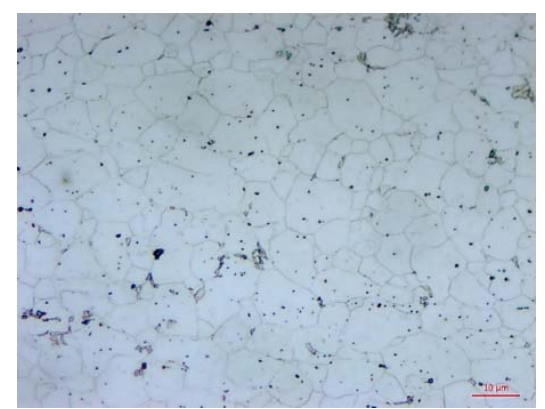

50A.A - Center (1000X) / d $\approx 6,8 \mu \mathrm{m}$

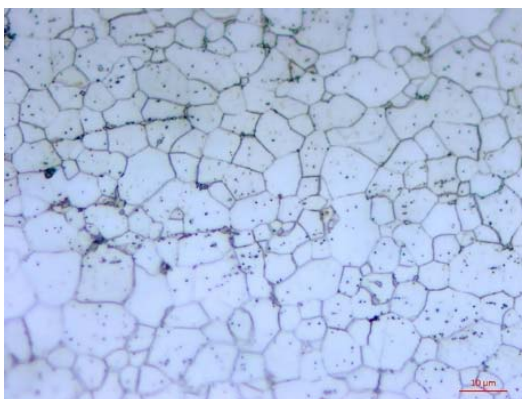

50A.A - Near surface (1000X) / d $\approx 5,6 \mu \mathrm{m}$

Figure 14. Micrographs of abnormal sample 50A.A ( $2 \%$ Nital Etch). The average grain size (d) are indicated.

Some of these samples was submerged for 24 hours in brine, a solution of salt (sodium chloride) in water. After this period, the samples were observed by optical microscope and all treated samples presents an dark surface due oxidation. Figure 15 shows a comparison between the treated samples and non-treated samples. The treated sample presents a dark colored surface in the cracked areas of the 
galvalume/aluzinc layer, whereas the non-treated show a bright aspect with no dark areas.
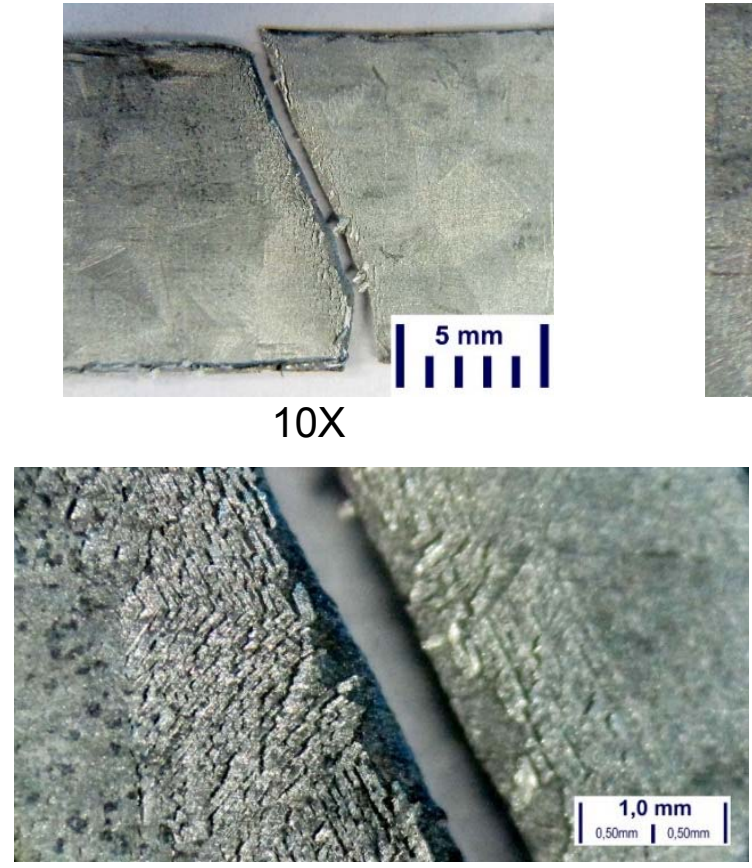

40X

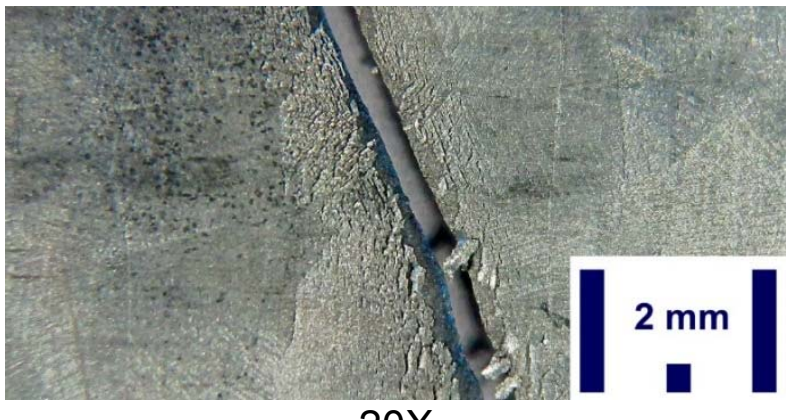

$20 X$

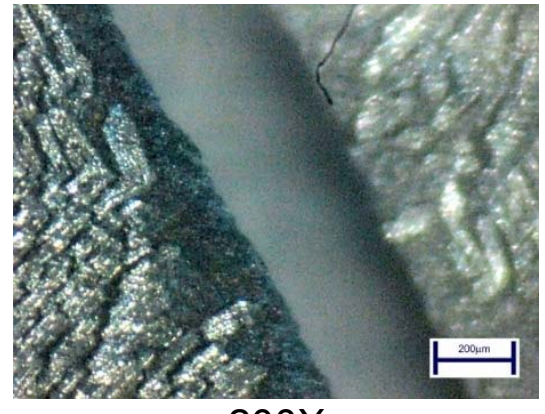

$200 X$

Figure 15. The same tensile test sample but with the right side obtained directly from test and the left side after treatment by submersion on brine during 24 hours followed by 48 hours exposed in fresh air.

\section{CONCLUSION}

The dark aspect observed on the coils surfaces can be associated to hydrated aluminum oxide $\left(\mathrm{Al}_{2} \mathrm{O}_{3} \cdot 3 \mathrm{H}_{2} \mathrm{O}\right)$ which has a yellow-brown-dark color. Tensile test samples were used to demonstrate this scenario. As the dark aspect observed on the coils surfaces can be associated to hydrated aluminum oxide $\left(\mathrm{Al}_{2} \mathrm{O}_{3} \cdot 3 \mathrm{H}_{2} \mathrm{O}\right)$, them it's possible to point out some practice to avoid or minimize the problem.

- In mild cases, a solvent (such as mineral spirits or turpentine) applied with a soft rag has been known to effectively remove the stain. This method is also used to remove stain from pre-painted Galvalume sheet without damaging the paint.

- For more advanced cases on unpainted Galvalume sheet, it is impossible to remove the stain without also affecting the good coating under and around the stained area. The amount of damage to the coating during removal will depend on the method used. In this case, storage stain can be removed from bare Galvalume sheet with a mild household cleanser and a wet sponge or rag (as they used for aluminum home objects cleaning). Industrial products may also be used, but are more aggressive to the coating.

In all cases, the Galvalume/Aluzinc sheet/tiles should be thoroughly rinsed with water after the stains have been removed.

\section{REFERENCES}

1 ASM Handbook Volume 08: Mechanical Testing and Evaluation, vol.08, Materials Park, 2000.

2 ASM Handbook Volume 09: Metallography and Microstructures, vol. 09, Materials Park, 2004. 
3 ASM Handbook Volume 10: Materials Characterization, vol. 10, Materials Park, 1986.

4 MORAIS, W. A.; MAGNABOSCO, A. S.; MENEZES NETTO, E. B. Metalurgia física e mecânica aplicada. $2^{a}$ Edição. São Paulo: ABM, 2009. v. 1 e 2. 942 p.

5 CALLISTER Jr., W.D.; Materials Science and Engineering: an Introduction. John Wiley \& Sons Inc., 4th ed., New York, 1997DIETER, G.E.; Mechanical Metallurgy. McGraw Hill Book Company, SI Metric Edtion, 1988.

6 MEYERS, M.A.; CHAWLA, K.K.; Principles of Mechanical Metallurgy. Prentice-Hall Inc., 1983.

7 WULPI, D.J. Understanding how components fail. American Society for Metals (ASM), 7th printing, 1993.. 